\title{
Characteristics and risk assessment of agricultural meteorological disasters based on 30 years' disaster data from Heilongjiang Province of China
}

\author{
Xing Zhenxiang ${ }^{1,2}$, Yang Zhaorui ${ }^{1}$, Fu Qiang ${ }^{1,2^{*}}$, Li Heng ${ }^{1,2}$, \\ Gong Xinglong ${ }^{1,2}$, Wu Jingyan ${ }^{1}$
}

(1. School of Water Conservancy and Civil Engineering, Northeast Agricultural University, Harbin 150030, China; 2. The Key Laboratory of High Efficiency Utilization of Agricultural Water Soil Resources of the Ministry of Agriculture, Harbin 150030, China)

\begin{abstract}
To determine the influence of agricultural meteorological disasters on agriculture in Heilongjiang Province, the disaster areas associated with different types of disasters and their variation characteristics were analyzed based on the statistical data of agricultural disasters from 1983 to 2013 in Heilongjiang Province, China. The moving average and the Mann-Kendall test were applied to identify the variation trends of drought, flooding, hailstorms and freezing (based on the disaster ratio and the disaster intensity index). Then, the Morlet wavelet analysis method was used to identify the periodicity of these four kinds of agricultural meteorological disasters. Finally, a fuzzy comprehensive evaluation method was adopted to analyze the degrees of agricultural loss induced by these disasters. The following results were obtained: 1) The disaster ratio and disaster intensity index for drought exhibited increasing trends; the disaster ratio and disaster intensity index for flooding exhibited decreasing trends; for hailstorms, the disaster ratio exhibited no obvious trend of change, whereas the disaster intensity index exhibited an increasing trend; and for freezing, the disaster ratio also exhibited no obvious trend of change, whereas the disaster intensity index exhibited a decreasing trend. 2) Mutation points were observed in the disaster ratio series for drought, flooding and hailstorms, whereas no mutation point was evident in the disaster ratio series for freezing. 3) Multiple time-scale characteristics were observed in the disaster ratio series for all four types of agricultural meteorological disasters. Furthermore, the disaster ratio series for the different types of disasters had different main periodicities. 4) From the perspective of the degree of agricultural loss induced by each type of disaster, drought was identified as the most severe type of agricultural meteorological disaster, followed by flooding, freezing, and hailstorms. The degree of agricultural loss caused by each type of disaster was different during different periods. Finally, based on the results, several strategies were identified for mitigating the effect of agricultural meteorological disasters in Heilongjiang Province.
\end{abstract}

Keywords: agricultural meteorological disaster, disaster risk assessment, disaster ratio, disaster intensity index, fuzzy comprehensive evaluation, agricultural loss

DOI: $10.25165 /$ j.ijabe.20171006.2537

Citation: Xing Z X, Yang Z R, Fu Q, Li H, Gong X L, Wu J Y. Characteristics and risk assessment of agricultural meteorological disasters based on 30 years' disaster data from Heilongiiang Province of China. Int J Agric \& Biol Eng, 2017; 10(6): 144-154.

\section{Introduction}

The problem of food security is a major strategic

Received date: 2016-04-18 Accepted date: 2017-10-10

Biographies: Xing Zhenxiang, PhD, Associate Professor, research interest: agricultural disasters analysis and evaluation, Email: zxxneau@ hotmail.com; Yang Zhaorui, Master, research interest: agricultural disasters analysis and evaluation, Email: 531395179@ qq.com; Li Heng, PhD, research interest: water resources analysis, Email: mr.liheng@gmail.com; Gong Xinglong, $\mathrm{PhD}$, research interest: hydrological simulation, Email: 121812305@qq.com; issue related to national economic security and the livelihood of citizens. Heilongjiang Province, as one of the major grain-producing areas and one of the most

Wu Jingyan, Master, research interest: agricultural water resources analysis, Email: 529413668@qq.com.

*Corresponding author: Fu Qiang, PhD, Professor, research interest: agricultural water resources analysis. Northeast Agricultural University, No.600, Changjiang Road, Xiangfang District, Harbin 150030, China. Tel: +86-451-55190209, Email: fuqiang@neau.edu.cn. 
important commodity grain production bases in China, plays a critical role in ensuring the food security of China. With the warming of the global climate and the increasing frequency of extreme climate events, the reductions in grain production are becoming increasingly serious due to the drought, flooding, hailstorms, freezing and other agricultural meteorological disasters in Heilongjiang Province. In 2012, agricultural meteorological disasters affected a total of 7.078 million people; the affected crop area was 2.43 million $\mathrm{hm}^{2}$; the disaster area was 134 thousand $\mathrm{hm}^{2}$; and the direct economic loss was 6.43 billion Yuan (RMB) ${ }^{[1]}$. In 2013, agricultural meteorological disasters affected a total of 6.669 million people; the crop affected area was 2.734 million $\mathrm{hm}^{2}$; the disaster area was 829 thousand $\mathrm{hm}^{2}$; and the direct economic loss was 32.52 billion Yuan (RMB). Compared with 2012, the affected area, the disaster area, and the direct economic loss all increased in $2013^{[2]}$. Therefore, it is significant to study the characteristics of disasters and the effect on agriculture for disaster prevention and control.

In recent years, more attention has been paid to agricultural meteorological disasters which are likely to become more frequent and more severe under the climate change ${ }^{[3-5]}$. To figure out the characteristics of agricultural meteorological disaster can provide references for decision-making to reduce agricultural loss by meteorological disasters. The types of agricultural meteorological disaster and the impact degree on agricultural loss vary for different regions. The disasters lead to deleterious impacts on various sectors of agriculture. The immediate impact of disaster is on crop area, crop production and farm employment ${ }^{[6]}$. It is more convenient to recognize degree of effect by analyzing the area and intensity change characteristics of different type of disasters, and then the measures for preventing disasters can be taken according the degree of effect on area and intensity of crop from different disasters ${ }^{[7]}$. Ten types of disasters including flood, drought, freeze, hail, etc. were selected to research their effects and its change characteristics on agricultural vegetation in the northern China over the past fifty years $^{[8]}$. It was found that the proportion of average affected agriculture area and average failure agriculture area of China that caused by drought, flood and was all over $70 \%$. In Heilongjiang Province, drought and flood are the main causes for destroying agriculture production almost in every year ${ }^{[9,10]}$, and the affected area of disasters vary from year to year, which showed high variability and different changing trends ${ }^{[11]}$. So the affected area and the failure area can be used to analyze the disaster destroy on agriculture ${ }^{[12,13]}$.

At present, main methods used in agricultural meteorological disaster risk assessment can be summarized into three categories: methods based on the comprehensive evaluation of indicators, methods based on the probability assessment of data and methods based on scenario simulations ${ }^{[14-18]}$. Some works were done on disasters in Heilongjiang Province, the effect on agricultural caused by the drought and flood were studied by the grey correlation or grey system and a fuzzy comprehensive evaluation $(\mathrm{FCE})^{[17-19]}$.

The main objectives of this study were to analyze the disaster area affected by main agricultural meteorological disasters in Heilongjiang Province. The disaster ratio and the disaster intensity index ${ }^{[19]}$ were used to analyze the variational characteristics of the disaster intensity of agricultural meteorological disasters. And then, a fuzzy comprehensive evaluation (FCE) method was applied to evaluate the degrees of agricultural loss induced by drought, flood, hailstorms, and freezing disasters. The structure of this paper is shown in Figure 1.

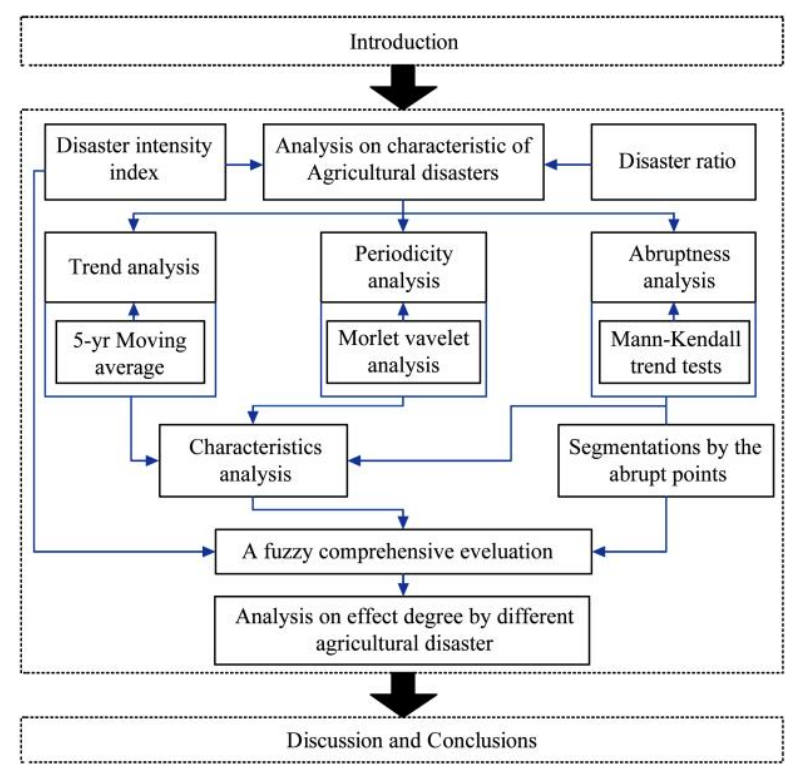

Figure 1 Schematic diagram of the manuscript structure 


\section{Methodology}

\subsection{Data source}

The study area is Heilongjiang Province, which is located in the range of $43^{\circ} 25^{\prime}-53^{\circ} 33^{\prime} \mathrm{N}$ and $121^{\circ} 11^{\prime}-$ $135^{\circ} 05^{\prime} \mathrm{E}$ (Figure 2). It is a northeastern province in China. It belongs to a boreal temperate climate and a humid to semi-humid continental monsoon climate, with an average annual temperature of $-4^{\circ} \mathrm{C}$ to $5^{\circ} \mathrm{C}$. The temperature gradually decreases from the southeast to the northwest, with a difference of nearly $10^{\circ} \mathrm{C}$ between the north and the south. The average annual precipitation ranges from $450 \mathrm{~mm}$ to $550 \mathrm{~mm}$, and the number of annual hours of sunshine generally ranges from $2300 \mathrm{~h}$ to 2800 h. In summer, the region has increasing temperature, precipitation and daylight.

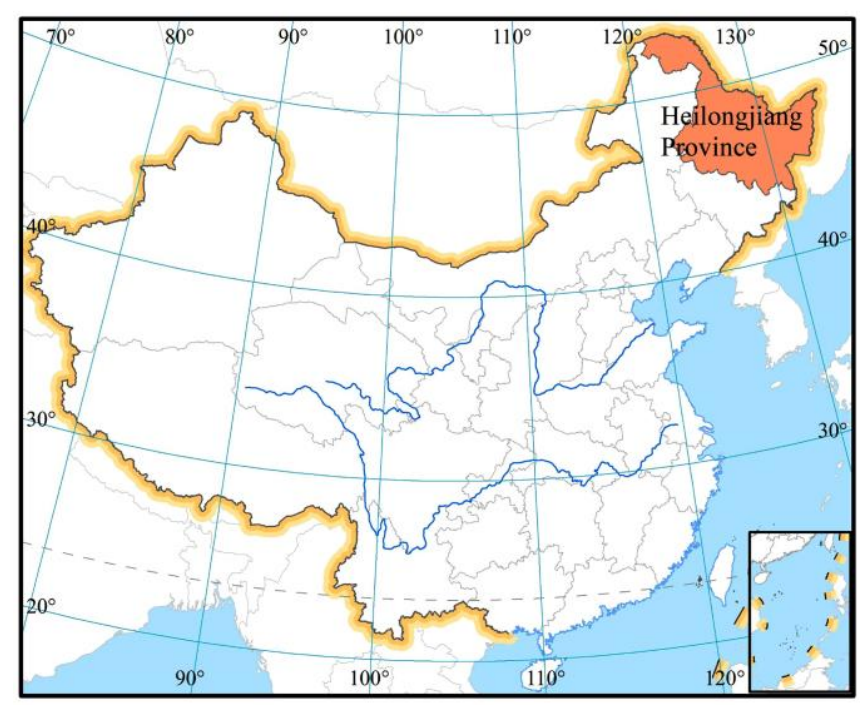

a. Location of Heilongjiang Province in China

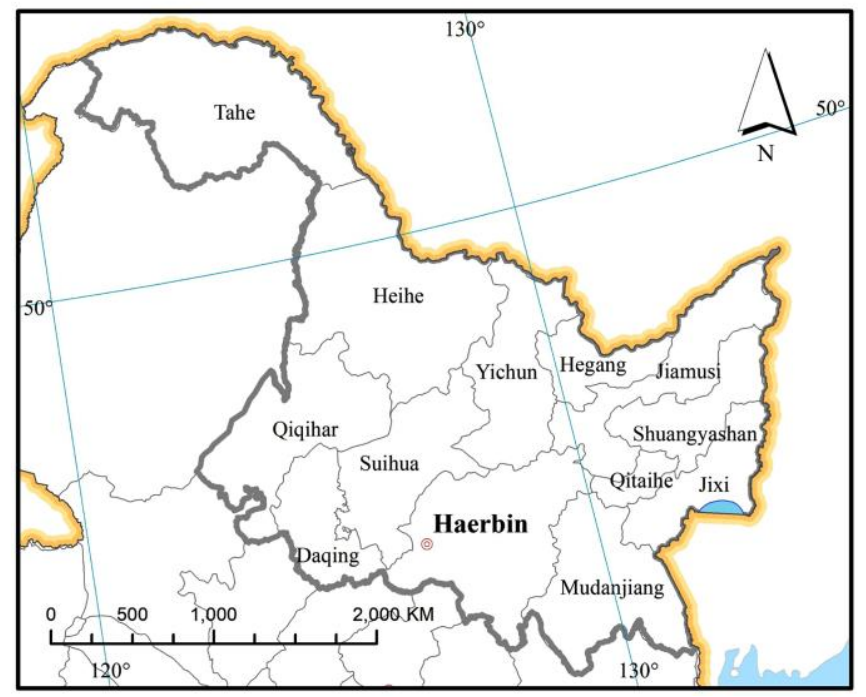

b. Districts in Heilongjiang Province

Figure 2 Location of study area
In this study, the data of the affected areas, disaster areas and planting areas were extracted from the China Statistical Yearbook (1983-2013), the China Agricultural Yearbook (1983-2013), the China Rural Statistical Yearbook (1983-2013) and the Heilongjiang Statistical Yearbook (1983-2013). The affected areas were defined as the agricultural production in a given year reduced by $1 \%$ compared with that in a normal year due to the disaster, including drought, flooding, hailstorms and freezing. Similarly, the disaster areas were defined as $3 \%$ reduction of agricultural production.

\subsection{Methods}

For distinguishing different meteorological disasters on agriculture production, the disaster ratio is shown in Equation (1):

$$
r=\frac{a}{b}
$$

where, $a$ is the area affected by a particular type of agricultural disaster and $b$ is the total planting area.

Similarly, the disaster intensity index, defined as the ratio of the disaster area to the affected area in a given year ${ }^{[20]}$, was introduced to describe the degree of severity of a given meteorological disaster. The disaster intensity index is shown in Equation (2):

$$
i=\frac{c}{a}
$$

where, $c$ is the disaster area.

In this study, firstly, a moving average ${ }^{[21]}$ was applied to identify the trends of variation in drought, flooding, hailstorms and freezing as a whole (based on the disaster ratio and the disaster intensity index). Secondly, the Mann-Kendall test ${ }^{[22]}$ was employed to estimate the mutation points within the global trends of variation in drought, flooding, hailstorms and freezing. Then, in order to catch the characteristic of periodicity for the four type disasters, a Morlet wavelet analysis method ${ }^{[23]}$ was used to identify the periodicity of the four types of agricultural meteorological disasters. Finally, in order to eliminate the effect of mutation points on the estimation of agricultural loss, a whole series of each disaster evaluation index was divided into several subseries and based on the mutation points, a $\mathrm{FCE}^{[24]}$ method was adopted to analyze the degree of agricultural 
loss caused by each type of disaster in Heilongjiang Province during the period of 1983-2013.

\section{Results and analysis}

\subsection{Varying characteristics and causal analysis}

\subsubsection{Agricultural disaster ratio analysis}

The disaster ratio of drought during the period of 1983-2013 exhibited a significant increasing trend with a slope of $0.31 \%(p<0.05)$ (Figure 3a). The disaster ratio curve for drought can be divided into three stages: the first stage was from 1983 to 1990, during which time the disaster ratio of drought ranged between 0 and 33\%; the second stage was from 1991 to 1999 with disaster ratio between $8 \%$ and 30\%; and the third stage was from 2000 to 2013 with notably increasing disaster ratio between 0 and $60 \%$. In 2004, the disaster ratio of drought increased by $45 \%$ because the winter precipitation was less by approximately 3\% throughout Heilongjiang Province, and $6 \%$ in certain areas. In 2005, it was rainy in Heilongjiang Province, the disaster ratio of drought reached its minimum of $3.87 \%$, and maximum of $54.63 \%$ in 2007. The average disaster ratio of drought was highest in the third stage; during this stage, it was higher than in the first and second stages by $10 \%$ and $15 \%$, respectively.

The annual disaster ratio of flooding was less than that of drought; moreover, it exhibited a decreasing trend during the period of 1983-2013, with a slope of $0.68 \%$ (Figure 3b). From the early 1980s to the early 21st century, the disaster ratio of flooding underwent a large relative change, reaching its maximum of $40.88 \%$ in 1988 . From 2000 to 2013, the disaster ratio of flooding ranged between 0 and $15 \%$.

The disaster ratio of hailstorms exhibited only a slight increasing trend (Figure 3c). From 1983 to 2001, the disaster ratio of hailstorms ranged between 0 and $8 \%$, and it subsequently increased greatly between 2002 and 2013. In 2002, the disaster ratio of hailstorms reached its maximum of $15.98 \%$.

Freezing disaster, the fourth type of agricultural meteorological disaster considered in this study, correspond to periods of sustained low temperatures due to strong cold air from the Polar Vortex and cold invasion, which cause crop damage, resulting in reduced production. The disaster ratio of freezing exhibited a slight decreasing trend (Figure 3d). It reached the highest value of $10.99 \%$ in 2002; from 1983 to 1991 and from 2005 to 2013, the disaster ratio of freezing ranged only between 0 and 4\%, remaining rather stable. From 1994 to 2000, the disaster ratio of freezing ranged between 0 and $6 \%$.
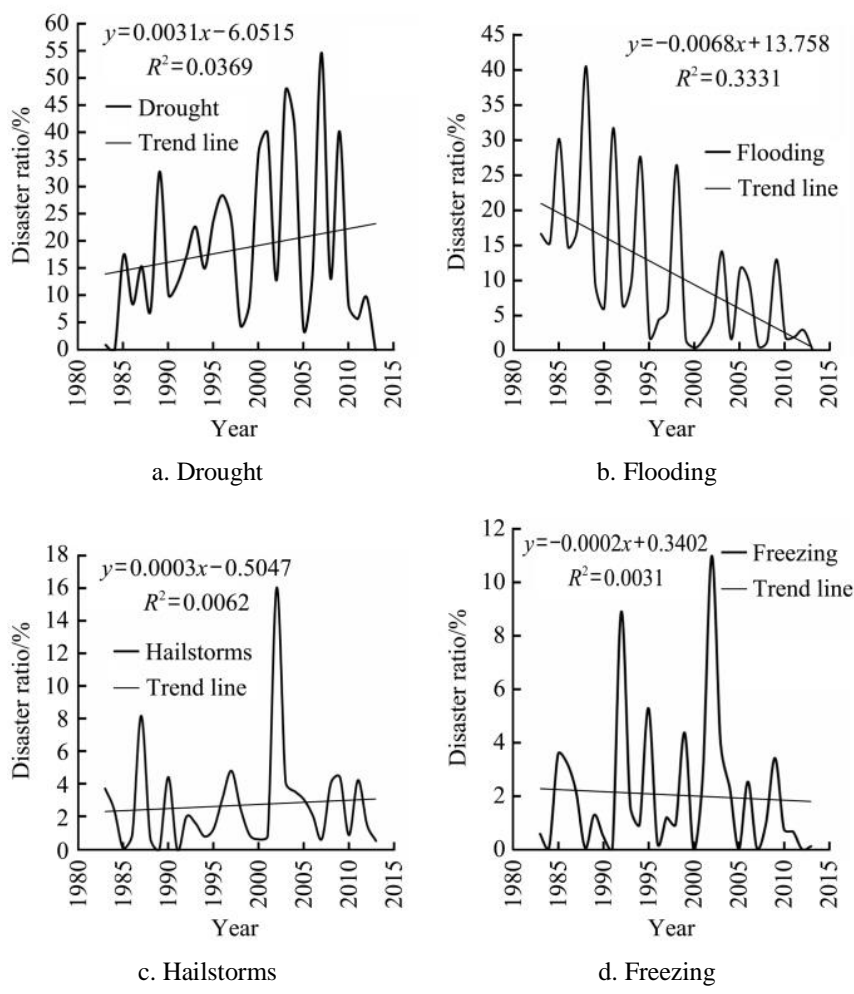

Figure 3 Trends of variation in agricultural meteorological disaster ratios in Heilongjiang Province

According to the above comprehensive analysis, the disaster ratio of drought showed a significant increase trend $(p<0.05)$, however, notable decrease in floods. Besides, no obvious variation trends of hailstorms and frozen were observed during 1983 to 2013.

Because most of the irrigation area was irrigated with surface water, which depends on the water volume in the dry season, the robustness of the irrigation water supply for avoiding reduced crop production was low ${ }^{[25]}$. Therefore, the disaster ratio of drought exhibited an increasing trend while the disaster ratio of flooding exhibited a decreasing trend, showed the reciprocal change trend, which is the new features of drought and flooding in Heilongjiang province in nearly 30 years. 
The results was similar with the researches by Lin et al. ${ }^{[26]}$ and Zhou et al. ${ }^{[27]}$, indicating that the overall meteorological disaster status of the study area was associated with a period of relative drought. Since the 1980s, the global climate has been warming, and Heilongjiang Province is located at high latitudes, where the average temperature has risen by nearly $1.4^{\circ} \mathrm{C}$ in the past 120 years. The temperature at high latitudes has become significantly higher. Meanwhile, the disaster ratios for hailstorms and freezing exhibited no obvious trends of change.

\subsubsection{Analysis of the disaster intensity index}

To horizontally compare the degree of severity of a given agricultural meteorological disaster according to the disaster intensity index during the period of 1983-2013, the linear trends in the disaster intensity indices for the four types of agricultural meteorological disasters were identified (Figure 4) and a 5-year moving average method ${ }^{[21]}$ was used to investigate the evolution of anomalous behaviors in the four types of agricultural meteorological disasters according to the 5-year moving averages (Figure 5). The disaster intensity index for drought and flooding displayed an increasing trend with a slope of $0.47 \%$ and $0.51 \%$ respectively (Figures 5a and 5b). Overall, the degrees of severity of drought and flooding tended to be high. The disaster intensity index for drought increased overall while exhibiting fluctuations, whereas the disaster intensity index for flooding decreased overall while exhibiting fluctuations. In 1985, 2001 and 2003, the degree of severity of flooding reached $77.7 \%, 74.2 \%$ and $76 \%$, respectively. According to the 5-year moving averages, the anomalies in the disaster intensity index for drought were negative and the degree of drought severity was lower during the period of 1983-1987 (Figure 5a). By contrast, during the transition from the 20th to the 21 st century, the 5-year moving averages indicate that the anomalies in the disaster intensity indices for flooding and drought were both positive, meaning that the degrees of severity of drought and flooding both increased during this period (Figures 5a and 5b).
The disaster intensity index for hailstorms showed an increasing trend with a slope of $1.12 \%$. After 1993, the average degree of hailstorms severity was consistently high (Figure 4c). The disaster intensity index for freezing exhibited a decreasing trend with a slope of $0.31 \%$. In 1984, 1996, 2004 and 2008, the degrees of severity of freezing disasters were higher than those in a normal year during the period of $1983-2013$ by $20 \%$ (Figure 4d). The 5-year moving averages indicate that the anomalies in the disaster intensity indices for hailstorms and freezing were both negative during the period of 1988-1991, meaning that the degrees of severity of hailstorms and freezing decreased during this period (Figures 5c and 5d).

According to the above analysis, on the whole, the disaster intensity indices of drought and hailstorms showed increasing trends with slopes of $0.47 \%$ and $1.12 \%$, respectively, whereas the disaster intensity indices for flooding and freezing exhibited decreasing trends with slopes of $0.51 \%$ and $0.31 \%$, respectively. Thus, the degrees of severity of drought and hailstorms were increasing and the degrees of severity of flood and freezing were decreasing during the period of 1983-2013.
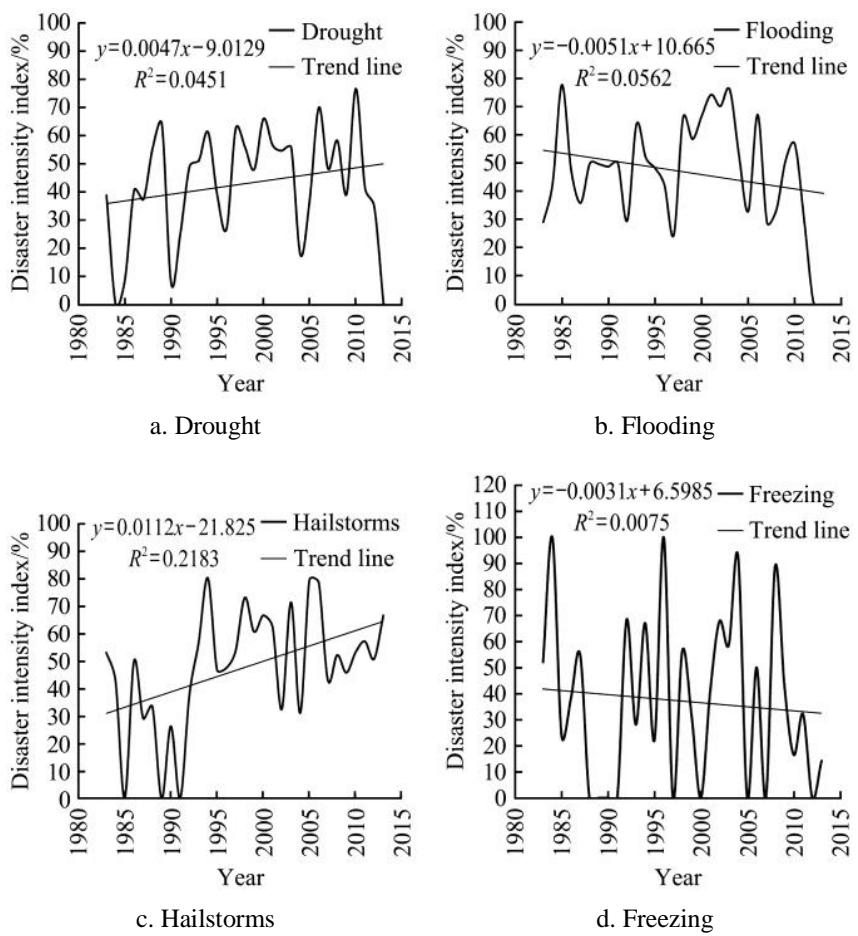

Figure 4 Trends of variation in agricultural meteorological disaster intensity indices in Heilongjiang Province 

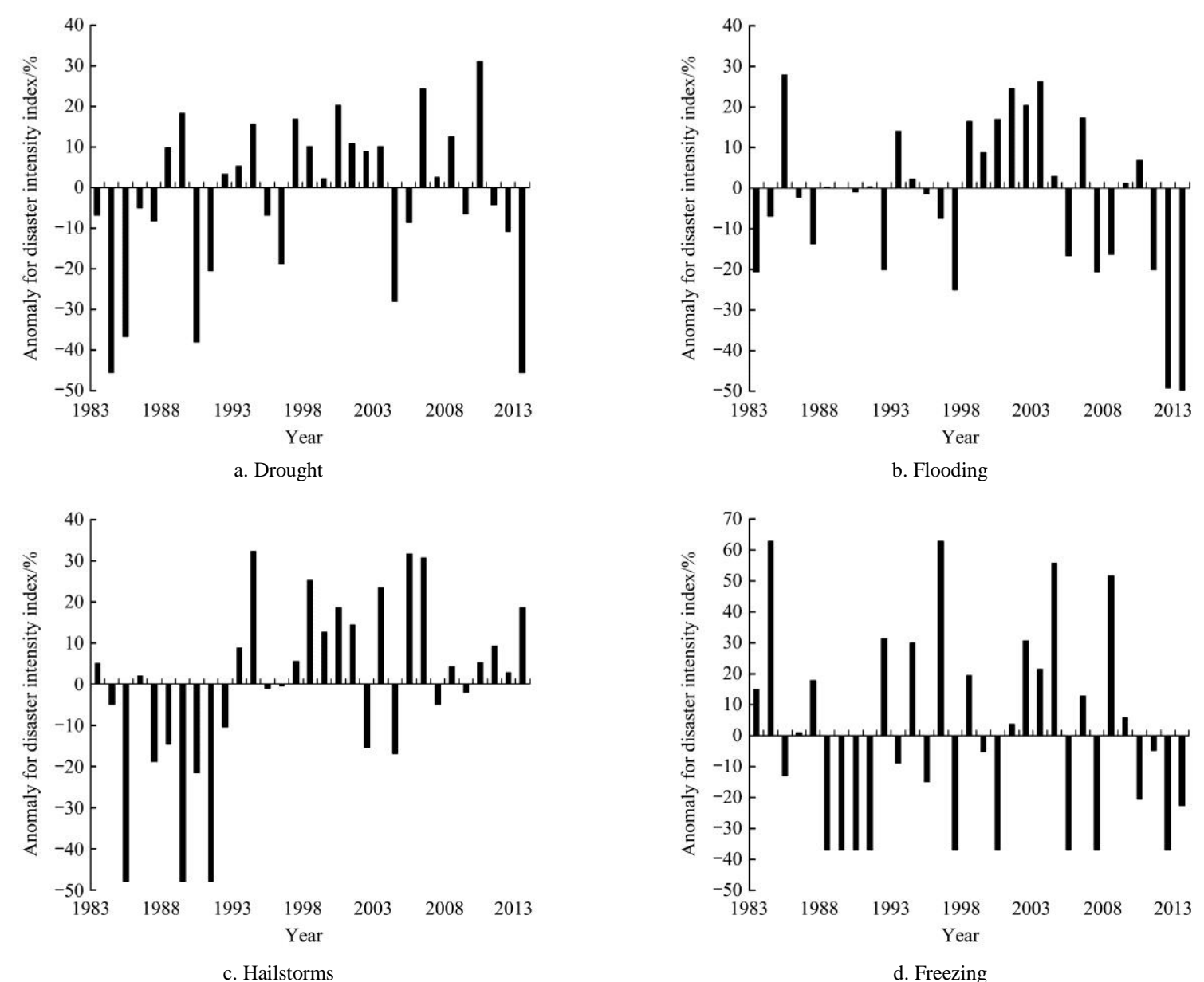

Figure 5 Variations in anomalous conditions as indicated by the 5-year moving averages of disaster intensity indices in Heilongjiang Province

\subsection{Analysis of abrupt changes}

To analyze the abruptness of the changes in the four considered types of agricultural meteorological disasters, the Mann-Kendall test was applied to each disaster ratio time series (Figure 6) to identify where the trend was significant at a confidence level of $95 \%$ (UF statistic < 1.96). Figure 6a shows the results of the Mann-Kendall test for drought disasters for the detection of potential abrupt changes over the period of 1983-2013. An intersection point between the UF and UB curves was detected in 1984, which was within the confidence zone. After 1994, however, the UF statistic exceeded 1.96, indicating a significant increasing trend at a confidence level of $95 \%$. An intersection point between the UF and UB curves was found in 1994, and after 1999, the UF statistic exceeded -1.96 for flood disasters from 1983 to 2013, which indicated a significant decreasing trend at a confidence level of $95 \%$ in Figure 6b. For hailstorm disasters, there was an intersection point at 1996 between the UF and UB curves in Figure $6 c$ by the detection of potential abrupt changes over the period of 1983-2013. As Figure 6d shows, the UF and UB curves for freezing disasters repeatedly intersected the boundary line while remaining between \pm 1.96 , indicating no significant point of abrupt change for freezing disasters.

In accordance with the abrupt change (mutation) points identified above, the stages of variation of each agricultural meteorological disaster were analyzed. The average disaster ratios were calculated for each disaster during the period of 1983-2013. The average disaster ratio of drought was $0.50 \%$ before 1984 and $19.86 \%$ after 1984. It can be concluded that the average disaster ratio of drought increased by $19.36 \%$, indicating a significant increase in the drought affected area. By contrast, the average disaster ratio of flooding was $18.84 \%$ before 1994 and $5.51 \%$ after 1994, corresponding to a decrease in the average disaster ratio of flooding by $13.33 \%$, which indicates a significant decrease in the flood affected area. The average disaster ratio of hailstorms was $2.10 \%$ before 1996 and 3.23\% after 1996, indicating an increase in the 
hailstorms affected area. No significant mutation point was identified for freezing disasters; the average disaster ratio of freezing was $2.04 \%$.
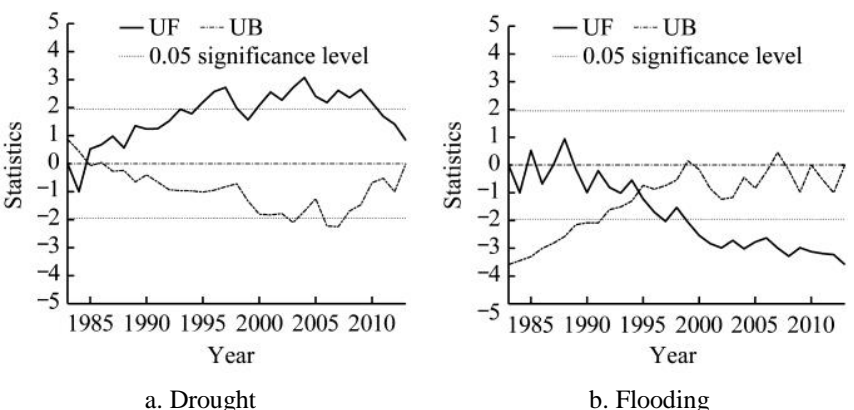

a. Drought

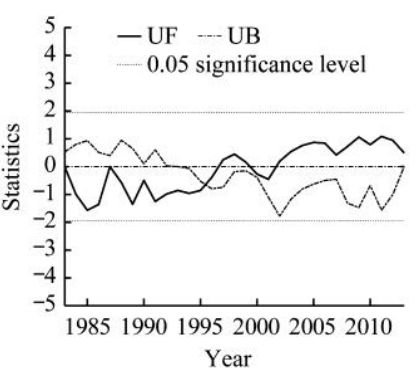

c. Hailstorms

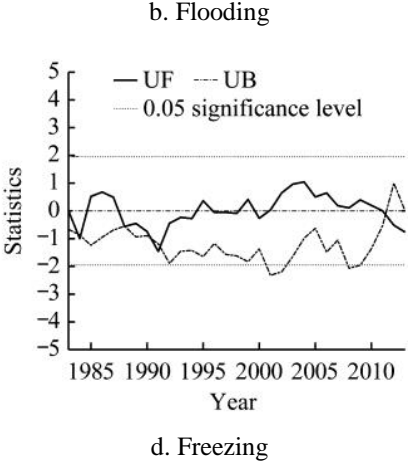

Figure 6 Curves of the Mann-Kendall statistics for agricultural meteorological disaster ratios in Heilongjiang Province

3.3 Analysis of the periodicity of agricultural meteorological disasters

Figures 3 and 4 show that the disaster ratios for the

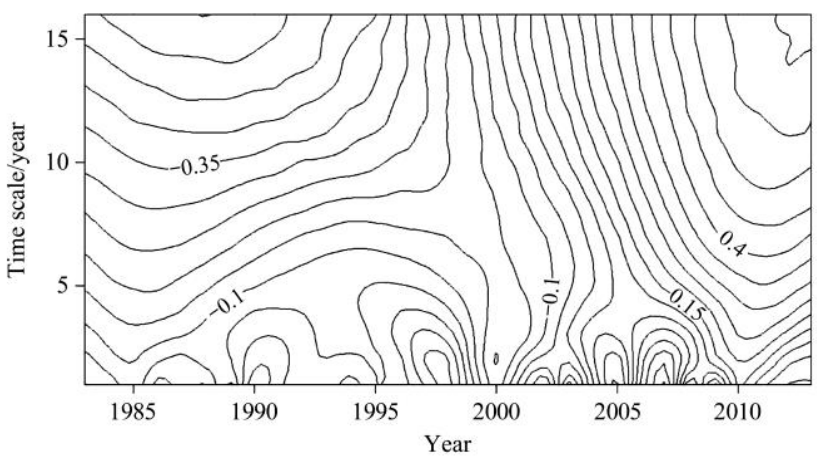

a. Drought

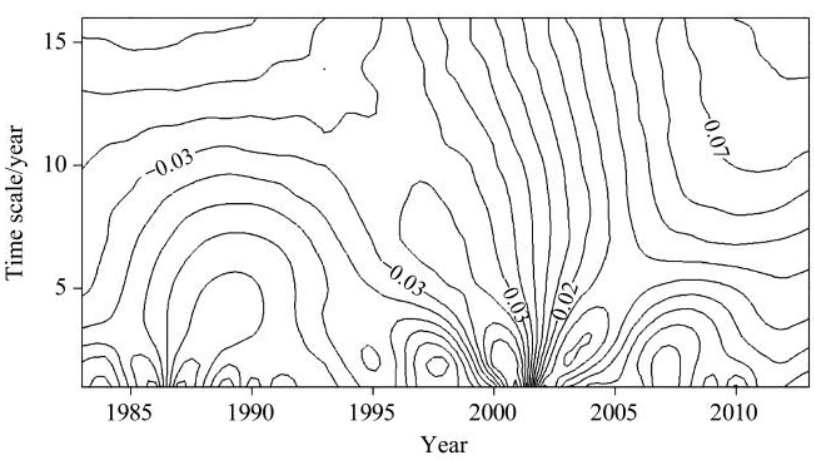

c. Hailstorms investigated types of agricultural meteorological disasters exhibited strong periodic variations. The Morlet wavelet analysis method was used to identify the periodicity of the disaster ratio of each of the four types of disasters; the contour maps of the real part of the wavelet coefficient of the agricultural meteorological disaster ratio are shown in Figure 7.

Figure $7 \mathrm{a}$ shows that the period of severe shocks in the disaster ratio of drought was between 0 and 5 years, whereas the disaster ratio of drought generally varied from small to large on a time scale of 5-15 years. By contrast, Figure $7 \mathrm{~b}$ shows that the disaster ratio of flooding experienced severe shocks on a time scale of between 7 years and 15 years, whereas it generally varied from small to large on a time scale of 0-7 years. As seen from Figure $7 \mathrm{c}$, the disaster ratio of hailstorms varied from small to large on time scales of 0-10 years, although this frequency was higher circa 2003, corresponding to a time scale of 0-5 years. Similarly, as seen from Figure $7 \mathrm{~d}$, the disaster ratio of freezing varied from small to large on time scales of 0-7 years, although this frequency was higher circa 1992 and 2002, corresponding to time scales of $0-5$ years.

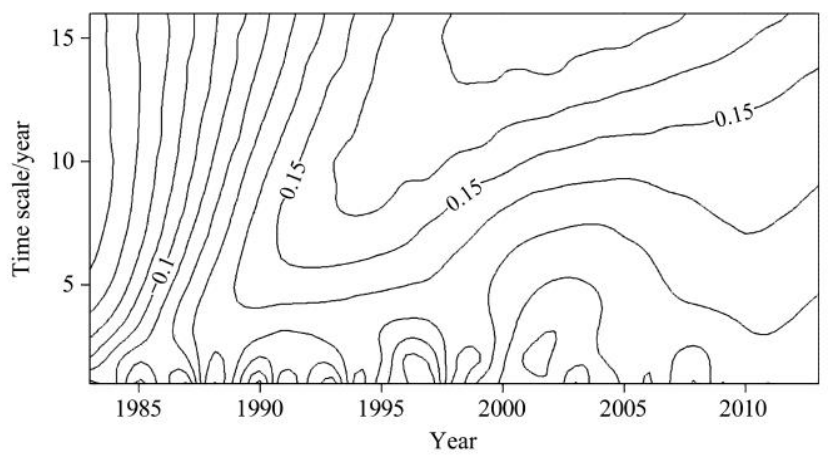

b. Flooding

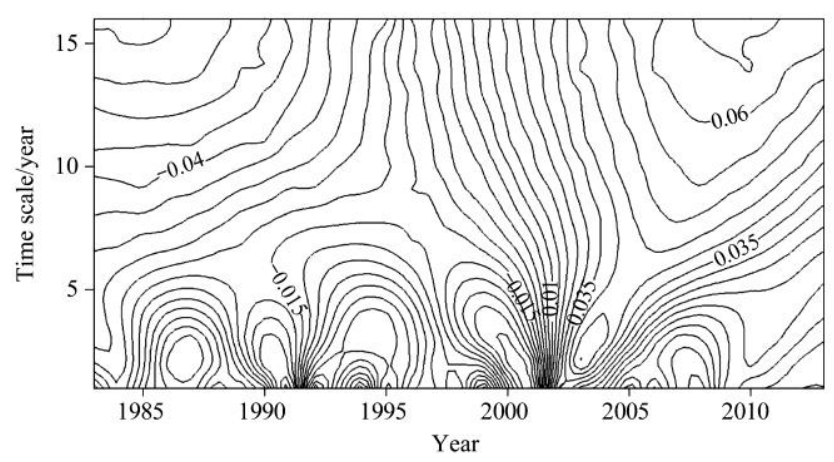

d. Freezing

Figure 7 Contour maps of the real part of the wavelet coefficient of the disaster ratio of agricultural meteorological disasters in Heilongjiang Province 
The variance of the wavelet transform coefficient was also calculated, as shown in Figure 8. In the case of drought disasters, three peaks were identified, corresponding to time scales of 3 years, 7 years and 14 years (Figure 8a). The first main period corresponded to the time scale of 3 years, whereas the peak values at 7 years and 14 years were associated with the second and third main periods, respectively (Figure 8a). For flood disasters, peaks at 3 years and 10 years were associated with the first and second main periods, respectively (Figure 8b); for hailstorm disasters, peaks at 3 years and 7 years were associated with the first and second main periods, respectively (Figure 8c); and for freezing disasters, peaks at 3 years and 8 years were associated with the first and second main periods, respectively
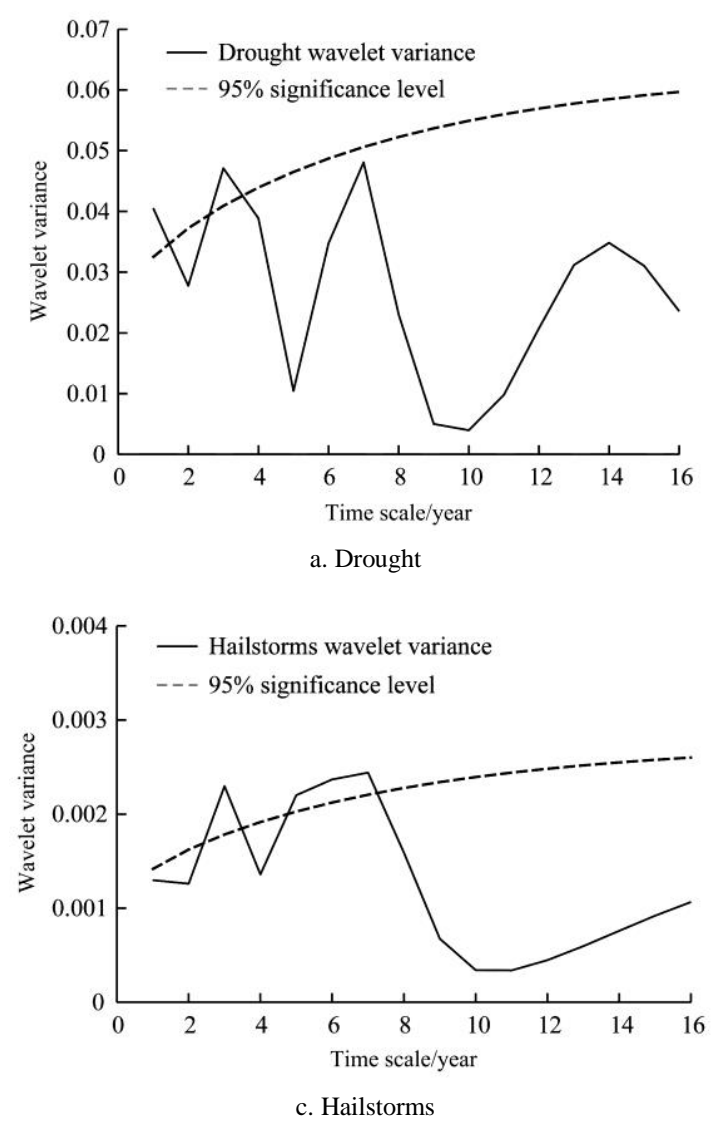

(Figure 8d). A significance test ${ }^{[28,29]}$ was applied to determine whether each of these main periods was statistically significant. As shown in 8a, only the peak at 3 years exceeded the confidence level of $95 \%$; thus, the true main drought period was 3 years. The peaks corresponding to 7 years and 14 years were below the $95 \%$ confidence level, indicating that the periodicities of 7 years and 14 years were not strong. In the curve shown in Figure 8b, only the peak at 3 years exceeded the confidence level of $95 \%$; thus, the true main period of flooding was also 3 years. Both main periods for hailstorms and freezing exceeded the $95 \%$ confidence level, indicating that all of the main periodicities identified for hailstorms and freezing were statistically significant.
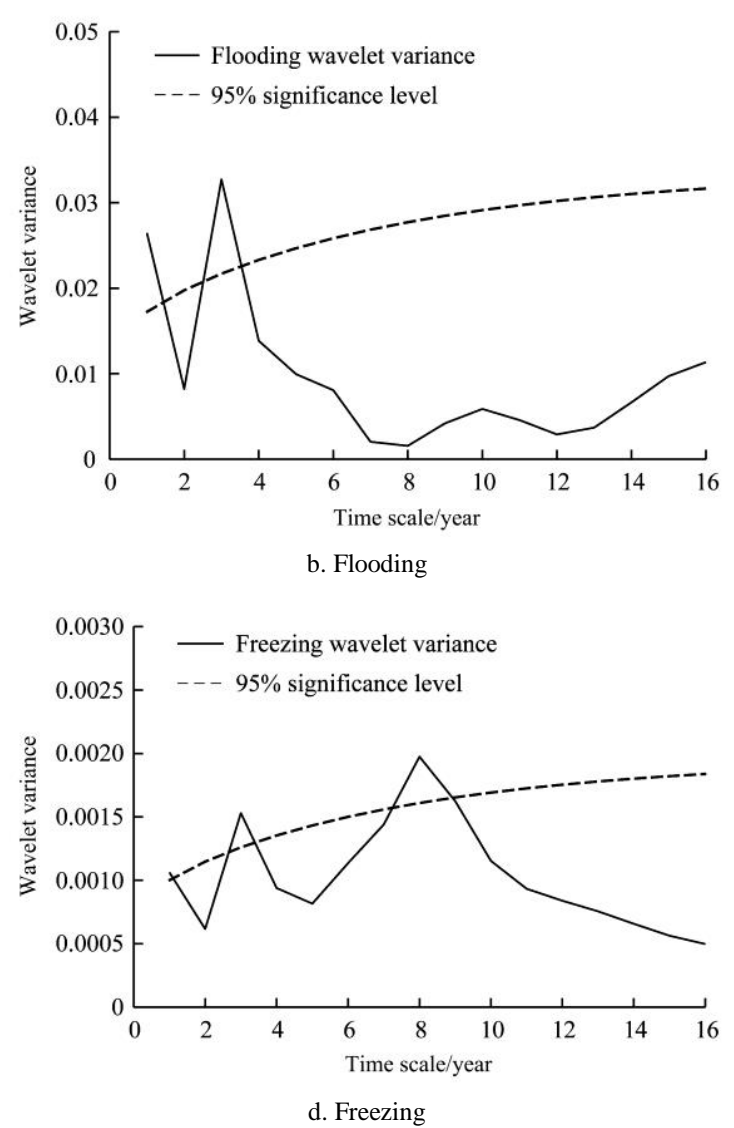

Figure 8 Curves of the wavelet variances for meteorological disaster ratios in Heilongiiang Province

\subsection{Analysis of disaster degree}

An FCE method was used to analyze the degree of agricultural loss induced by each type of disaster. In accordance with the concept of membership functions in fuzzy mathematics, the maximum value of each disaster ratio was used to represent the highest degree of disaster, under the assumption that a larger disaster ratio implies a higher degree of disaster. The membership function for each disaster was established with respect to the maximum disaster degree, the value of the membership function for each disaster was obtained, and the fuzzy relation matrix $R$ was constructed; then, normalization and ranking were performed after the fuzzy transformation. Considering the identified mutation 
points in the disaster ratios in Heilongjiang Province, the disaster ratios were divided into three periods based on the mutation points presented in Section 4.2, and then, a comprehensive evaluation set for the provincial agricultural disaster situation (Table 1) was constructed using the FCE method.

As shown in Table 1, drought was the type of agricultural meteorological disaster that caused the most agricultural loss in Heilongjiang Province during the period of 1983-2013, whereas the agricultural loss caused by hailstorms was minimal. From 1983 to 2013, the agricultural loss caused by flooding was higher than that caused by drought. Subsequently, the agricultural loss caused by flooding gradually decreased; the agricultural loss caused by freezing gradually increased, although it remained at only approximately $50 \%$ of the loss caused by the most influential disaster type; and the agricultural loss caused by drought increased in each period.

Table 1 FCE evaluation result of the agricultural loss induced by disasters in Heilongjiang Province

\begin{tabular}{lccccccc}
\hline \multirow{2}{*}{$\begin{array}{c}\text { Disaster } \\
\text { type }\end{array}$} & \multicolumn{2}{c}{$1983-1993$} & & \multicolumn{2}{c}{$1994-1995$} & & \multicolumn{2}{c}{$1996-2013$} \\
\cline { 2 - 4 } \cline { 5 - 7 } & $\begin{array}{c}\text { Evaluation } \\
\text { Set }\end{array}$ & Ranking & $\begin{array}{c}\text { Evaluation } \\
\text { Set }\end{array}$ & Ranking & $\begin{array}{c}\text { Evaluation } \\
\text { Set }\end{array}$ & Ranking \\
\hline Drought & 0.266 & 2 & 0.366 & 1 & 0.468 & 1 \\
Flooding & 0.428 & 1 & 0.324 & 2 & 0.144 & 4 \\
Hailstorms & 0.132 & 4 & 0.058 & 4 & 0.206 & 2 \\
Freezing & 0.174 & 3 & 0.252 & 3 & 0.182 & 3 \\
\hline
\end{tabular}

During 1983-1993, the ranking of the types of disasters in terms of the degree of agricultural loss they caused was flooding $>$ drought $>$ freezing $>$ hailstorms. During the period of 1994-1995, the high-to-low ranking of the disaster types in terms of the degree of agricultural loss was drought $>$ flooding $>$ freezing $>$ hailstorms. During the period of 1996-2013, the disaster degree ranking was drought $>$ hailstorms $>$ freezing $>$ flooding .

After 1994, the disaster degree ranking of drought in terms of agricultural loss rose from No.2 to No.1. The cause was a decrease in precipitation ${ }^{[30]}$ accompanied by relatively high temperatures, which led to excessive evaporation and transpiration; consequently, the degree of agricultural loss caused by drought in the 1990s was severe. The degree of agricultural loss due to flooding reached its minimum during the period of 1996-2013, which was related to construction for flood control engineering and field drainage systems. By contrast, the disaster degree ranking of hailstorms in terms of agricultural loss rose from No. 4 to No. 2 .

Overview the Table 1, the drought and flooding were taken important position with $60 \%-70 \%$ of the affected area among the four disasters. It was due to the uneven in time of precipitation in a whole year. There are about $70 \%$ of precipitations occurred from June to September, while the drought was often occurred from March to May in a year. So to control the natural disaster effect on agriculture, the first measure is that more water conservancy projects should be built to adjust the uneven situation of precipitation in time of a year.

\section{Conclusions and suggestions}

\subsection{Conclusions}

In this study, the characteristics of four types of agricultural meteorological disasters (drought, flooding, hailstorms and freezing) were analyzed based on disaster data related to agricultural meteorological disasters in Heilongjiang Province during the period of 1983-2013. The moving average and the Mann-Kendall test were used to analyze the variation characteristics of these agricultural meteorological disasters. Then, the Morlet wavelet analysis method was used to identify the periodicity of these disasters. Finally, an FCE method was applied to reveal the degree of agricultural loss associated with each type of agricultural meteorological disaster. The primary conclusions are as follows:

(1) During the period of 1983-2013, the disaster ratio of drought exhibited a significant increasing trend with a slope of $0.31 \%(p<0.05)$, the disaster ratio of flooding exhibited a decreasing trend with a slope of $0.68 \%$, and the disaster ratios for hailstorms and freezing exhibited no obvious trend of change. Mutation points in the disaster ratios for drought and flooding were identified in 1984 and 1994, respectively, and a mutation point in the disaster ratio of hailstorms was observed in 1996, whereas no mutation point was evident in the freezing disaster ratio series.

(2) During the period of 1983-2013, the disaster intensity indices for drought and hailstorms exhibited increasing trends with slopes of $0.47 \%$ and $1.12 \%$, 
respectively, and the disaster intensity indices for flooding and freezing exhibited decreasing trends with slopes of $0.51 \%$ and $0.31 \%$, respectively. Thus, the degrees of severity of drought and hailstorms were increasing during the period of 1983-2013, whereas the degrees of severity of flooding and freezing were decreasing.

(3) During the period of 1983-2013, multiple time-scale characteristics were evident in the disaster ratio series for all four types of agricultural meteorological disasters. The main periods for drought and flooding were both 3 years, two main periods of 3 years and 7 years were identified for hailstorms, and freezing disasters also exhibited two main periodicities of 3 years and 8 years.

(4) During the period of 1983-2013, drought played a major role in agricultural loss, whereas the agricultural loss caused by hailstorms was minimal. On the whole, the ranking of the disaster types in terms of the degree of agricultural loss they induced was as follows: drought, flooding, freezing, and hailstorms.

\subsection{Suggestions}

Based on the results above, firstly, agricultural disaster control management in Heilongjiang Province should focus on measures for mitigating the impact of drought, including strengthening the basic structure of agricultural water conservancy projects, taking steps to ensure the reasonable use of surface water and groundwater, and improving the robustness of the irrigation water supply. And if the grain yield in each districts can be get, the evaluation results may be more effective.

In addition, the driving factors and mechanism of drought and flooding should be further studied, and the field drainage facilities should be improved, and suitable flood detention basins should be designed and established to reduce loss caused by drought and flooding in the further. As a secondary priority, measures such as adjustment of planting structure, optimization of crop varieties should be taken to promote the development of technologies and facilities for protecting crops from freezing and hailstorms.

\section{Acknowledgments}

This work was supported by the National Key R\&D Program of China (No: 2017YFC0406004), the National Natural Science Foundation of China (No: 51109036, 51179032), the Natural Science Foundation of Heilongjiang Province of China (No: E2015024), the Research Fund for the Doctoral Program of Higher Education of China (No: 20112325120009), the Foundation for Reserve Academic Leader in Province Lead Team of Heilongjiang Province of China (No: 500001), the Research Foundation for Postdoctors of Heilongjiang Province of China (No: LBH-Q12147), the Projects for Science and Technology Development of Water Conservancy Bureau in Heilongjiang Province of China (No: 201402, No: 201404, No: 201501), and the Academic Backbones Foundation of Northeast Agricultural University (No.16XG11).

\section{[References]}

[1] Song L C. China Meteorological disaster yearbook. Beijing, China: Meteorological Press, 2013. (in Chinese)

[2] Sun S, Pei Y H, Wang C L, Liu D. Main meteorological disasters and the impact to Heilongjiang Province in 2013. Heilongjiang Agricultrue Science, 2014; 12: 153-155. (in Chinese)

[3] Li Y J, Wang C Y, Zhao B, Liu W J. Effects of climate change on agricultural meteorological disaster and crop insects diseases. Transactions of the CSAE, 2010; 26(Suppl1): 263-271. (in Chinese)

[4] Delgado J M, Apel H, Merz B. Flood trends and variability in the Mekong River. Hydrology and Earth System Sciences, 2010; 14(3): 407-418.

[5] Woodhouse C A, Overpeck J T. 2000 years of drought variability in the central United States. Bulletin of American Meteorological Society, 1998; 79(12): 2693-2714.

[6] Sesha M V R S, Murthy C S, Chandrasekar K, Jeyaseelan A T, Diwakap P G, Dadhwal V K. Agricultural drought: Assessment \& monitoring, Mausam, 2016; 67(1): 131-142.

[7] Punge H J, Kunz M. Hail observations and hailstorm characteristics in Europe: A review. Atmospheric Research, 2016; 176-177: 159-184.

[8] Xu X G, Xu L F, Yan L, Ma L Y, Lu Y L. Integrated regional ecological risk assessment of multi-ecosystems under multi-disasters: a case study of China. Environmental Earth Sciences, 2015; 74 (1): 747-758.

[9] Xie N M, Xin J H, Liu S F. China's regional 
meteorological disaster loss analysis and evaluation based on grey cluster model. Nature Hazards, 2013; 71(2): 1067-1089.

[10] Pei W, Fu Q, Liu D, Li T X, Cheng K. Assessing agricultural drought vulnerability in Sanjiang Plain based on an improved projection pursuit model. Nature Hazards, 2016; 82(1): 683-701.

[11] Du X D, Jin X B, Yang X L, Yang X H, Xiang X M, Zhou Y K. Spatial-temporal pattern changes of main agriculture natural disasters in China during 1990-2011. Journal of Geography and Science, 2015; 25(4): 387-398.

[12] Wang Z L, Wang J, Wang J S. Risk assessment of drought disaster in southern China. Discrete Dynamics in Nature and Society, 2015; (6): 1-8.

[13] Han W X, Liang C, Jiang B F, Ma W, Zhang Y. Major natural disasters in China, 1985-2014: occurrence and dangers. International Journal of Environmental Research and Public health, 2016; 13(11): 1-14.

[14] Wang C Y, Zhang J Q, Huo Z G, Guo J P, Li Y J. Prospects and progresses in the research of risk assessment of agrometeorological disasters. Journal Meteorological Research, 2015; 73(1): 1-19. (in Chinese)

[15] Wang Y, Huang G Q, Zhao Q G, Cai J J, Liu X P, Zhang Q. Characteristic analysis of agro-meteorological disasters and the impacts on grain yield in Guangxi. Journal of Agriculture, 2015; 5(3): 92-96. (in Chinese)

[16] Peng C M. Study on effect of agricultural meteorological disasters on grain yield in Henan Province through grey correlative degree analysis. Acta Agriculturae Jiangxi, 2017; 29(1): 106-110. (in Chinese)

[17] Zhang P, Wu J J, Li G L. Research on the construction of agricultural meteorological disaster prevention system in Heilongjiang Province. Management of Agriculture Science, 2011; 30(1): 62-65. (in Chinese)

[18] Tang L B, Zhang P, Wang J, Gu J. Risk assessment and prediction of agro-meteorological disasters in Heilongjiang Province. Journal of Heilongjiang Bayi Agricultural University, 2011; 23(2): 77-81. (in Chinese)

[19] Hu Y N, Li K, Xu Y L. Characteristic analysis of agricultural meteorological disasters and risk assessment of the crop loss in North China Plain during 1951-2010. Chinese Journal of Agrometeorology, 2013; 34(2): 197-203. (in Chinese)
[20] Wu Y F, Li M S, Jang W G. Change of drought condition in different economic regions and its relationship with fluctuation of gain yield per unit area. Journal of Natural Disaster Sicence, 2006; 15(6): 205-210.

[21] Ahani H, Kherad M, Kousari M R, Rezaeian-Zadeh M, Karampour M A, Ejraee F, et al. An investigation of trends in precipitation volume for the last three decades in different regions of Fars Province, Iran. Theoretical of Applied Climatology, 2012; 109(3-4): 361-382.

[22] Shadmani M, Marofi S, Roknian M. Trend analysis in reference evapotranspiration using Mann-Kendall and spearman's Rho tests in arid regions of Iran. Water Resources Managment, 2012; 26(1): 211-224.

[23] Bradshaw G A,McIntosh B A. Detecting climate-induced patterns using wavelet analysis. Environmental Pollution, 1994; 83(1-2): 135-141.

[24] Kumar A, Choi S, Goksel L. Tolerance allocation of assemblies using fuzzy comprehensive evaluation and decision support process. Internaltion Journal of Advanced Manufacuring Technology, 2011; 55(1-4): 379-391.

[25] Jin L,Wang Z B, Wang Y. Study on the problem of drought disaster in Heilongjiang Province. Heilongjiang Science and Technology of Water Conservancy, 2008; 36(5): 16-18. (in Chinese)

[26] Lin Y, Zhang T J, Fu F R. Comprehensive Production Capacity of Grain in Heilongjiang Province, Harbin: Heilongjiang Science and Technology Press, 1992. (in Chinese)

[27] Zhou C S. Influence of agricultural meteorological disasters on grain production in Heilongjiang province, Dissertation. Harbin: Heilongjiang University, 2010. (in Chinese)

[28] Torrence C, Compo G P. A practical guide to wavelet analysis. Bulletin of American Meteorological Society, 1998; 79(1): 61-78.

[29] Hao L S, Bi B G, Yao X X. Analysis of solar activities and changes. Journal Space Science, 2007; 27(4): 265-270. (in Chinese)

[30] Su X D, Zhang X P. Analysis on the variation character of temperature and precipitation and abrupt change in Heilongjiang in recent 56 years. Chinese Agricultural Science Bulletin, 2011; 27(14): 205-209. (in Chinese) 